\title{
PENGARUH PEMBERIAN MINUMAN ISOTONIS DAN PISANG \\ TERHADAP KADAR GLUKOSA DARAH ATLET TENIS LAPANGAN UNIVERSITAS NEGERI PADANG
}

\author{
Yogi Andria \\ Universitas Negeri Padang, Ilmu Keolahragaan, Padang, Indonesia \\ yogiandria@fik.unp.ac.id
}

\begin{abstract}
The problem in this study is that many athletes do not pay attention to nutrition and drinks consumed while playing tennis. It is feared that it can affect performance when competing, so it is necessary to do research on the nutrition and drinks consumed by field tennis athletes at Padang State University.

This study aims to determine the effect of giving isotonic drinks and bananas on blood glucose levels in tennis tennis athletes. The research method used was an experiment with the same subject design (treatment by subjects designs). The population in this study were tennis athletes in Padang State University totaling 35 people. The research sample of 20 male tennis athletes taken by purposive sampling technique. The instrument for measuring blood glucose levels uses the Glucometer. The data analysis technique used is ANOVA (one way) at a significant level $\alpha=0.05$. The results show that isotonic and banana drinks during playing tennis have not been able to maintain blood glucose levels, as evidenced by differences in blood glucose levels before and after playing tennis. Isotonic drinks are better at maintaining blood glucose levels after playing tennis compared to bananas with a significant difference $(p<0.05)$.
\end{abstract}

Keywords: Isotonic drinks, bananas, blood glucose levels

\begin{abstract}
Abstrak
Masalah dalam penelitian ini adalahbanyaknya atlet yang kurang memperhatikan nutrisi dan minuman yang dikonsumsi saat bermain tenis lapangan. Hal ini dikhawatirkan dapat mempengaruhi performa saat bertanding, sehingga perlu dilakukan penelitian terhadap nutrisi dan minuman yang dikonsumsi atlet tenis lapangan Universitas Negeri Padang.

Penelitian ini bertujuan untuk mengetahuipengaruh pemberian minuman isotonis dan pisang terhadap kadar glukosa darah atlet tenis lapangan. Metode penelitian yang digunakan adalah eksperimen dengan rancangan sama subjek (treatment by subjects designs). Populasi dalam penelitian ini adalah atlet tenis yang ada di Universitas Negeri Padang berjumlah 35 orang. Sampel penelitian berjumlah 20 atlet tenis putra yang diambil dengan teknik purposive sampling. Instrumen untuk mengukur kadar glukosa darah menggunakan alat Glucometer. Teknik analisis data yang digunakan adalah ANOVA (one way) pada taraf signifikan $\alpha=0,05$. Hasil menunjukkan pemberian minuman isotonis dan pisang selama bermain tenis lapangan belum dapat menjaga kadar glukosa darah, terbukti dari adanya perbedaan nilai kadar glukosa darah sebelum dan sesudah bermain tenis lapangan. Minuman isotonis lebih baik dalam menjaga kadar glukosa darah sesudah bermain tenis lapangan dibandingkan dengan pisang dengan perbedaan yang signifikan $(p<0,05)$.
\end{abstract}


Kata Kunci: Minuman Isotonis, Pisang, Kadar Glukosa Darah

\section{PENDAHULUAN}

Olahraga merupakan salah satu wadah untuk meningkatkan sumber daya manusia. Olahraga yang teratur dapat meningkatkan kualitas fisik dan mental seseorang.Permainan tenis lapangan merupakan olahraga yang dimainkan oleh dua atau empat orang pemain. Permainan tenis merupakan olahraga yang dapat dilakukan di lapangan terbuka maupun di lapangan tertutup. Aktivitas yang dilakukan dalam permainan tenis lapangan adalah panjang dan diselingi dengan waktu istirahat yang pendek. Panjangnya waktu pertandingan tidak bisa diketahui, yang menyebabkan seorang pemain bisa berada di lapangan antara satu sampai empat jam. Dalam waktu istirahat yang pendek pemain diharapkan bisa memulihkan kondisi dengan cepat dan menjaga performanyauntuk kembali melanjutkan permainan.

Masalah yang sering ditemukan pada pemain yang sedang bertanding adalah kelelahan. Banyak pemain yang tidak bisa mengatasi kelelahan yang dialami, atau ketidakmampuan untuk memulihkan kondisi pada saat waktu istirahat dalam pertandingan. Hal seperti ini akan berpengaruh terhadap menurunnya performa atau kinerja fisik.Pemberian cairan saat berolahraga berpengaruhterhadap kadar glukosa darah. Keseimbangan kadar glukosa darahmempengaruhi performa pemain saat bertanding. Menurunnya glukosa darah selama olahraga berat dan panjang juga menjadi penyebab utama terjadinya kelelahan.

Tersedianya glukosa darah sangat penting bagi atlet agar dapat mengembalikan simpanan glikogen hati dan otot dan mengatasi kelelahan (Hidayat, 2014). Selanjutnya menurut Irawan (2007) glukosa tidak hanya dapat tersimpan dalam bentuk glikogen di dalam otot dan hati, namun juga dapat tersimpan pada plasma darah dalam bentuk glukosa darah. Selain akan berperan sebagai bahan bakar bagi proses metabolisme, glukosa juga berperan sebagai sumber energi utama bagi kerja otak. Apabila kadar glukosa darah menurun, fungsi sel otak terganggu karena sel saraf tidak menyimpan karbohidrat, akibatnya akan berdampak pada penurunan performa atlet.

Saat sekarang ini, telah banyak ditemukan jenis minuman yang dikonsumsi saat berolahraga atau disebut sport drink, salah satunya adalah minuman isotonis. Minuman isotonis mengandung elektrolit, glukosa dan karbohidrat yang banyak dikonsumsi oleh para olahragawan. Pemberian minuman yang mengandung glukosa sebelum, saat dan setelah aktivitas fisik diharapkan dapat menjaga gula darah agar tidak terjadi hypoglikemia (kadar gula darah rendah) saat beraktivitas fisik. Selain itu, 
untuk menjaga performa saat bertanding yaitu dengan mengonsumsi buah-buahan, salah satunya adalah buah pisang.Pisang kaya akan mineral seperti kalium, magnesium, fosfor, besi dan kalsium. Pisang juga mengandung vitaminyaitu B, B6 dan $\mathrm{C}$ sertaserotonin yang aktif sebagai neurotransmiter dalam kelancaran fungsi otak (Prabawati, 2008).

Dari pantauan peneliti di lapangan, banyak pemain yang mengalami penurunan performa dan sulit untuk mengatasi kelelahan saat bertanding. Hal ini terlihat dari kesalahan teknik pukulan yang dilakukan, dan juga menurunnya kecepatan reaksi pemain saat mengantisipasi bola dari lawan. Semua itu disebabkan oleh kurangnya asupan cairan dan nutrisi yang dikonsumsi saat waktu istirahat, dan pemilihan minuman yang kurang sesuai untuk lebih cepat dalam mengganti cairan tubuh yang hilang, serta lebih memberi tenaga kepada pemain yang berguna untuk menunda kelelahan.

\section{METODE}

Penelitian ini merupakan jenis penelitian eksperimen dengan rancangan sama subjek (treatment by subjectsdesigns). Dalam rancangan sama subjek beberapa jenis atau variasi treatmentdiberikan secara berturut-turut kepada sekelompok subjek yang sama, dan sekaligus menjadi grup kontrol (same group)(Hadi, 2004). Sampel pada penelitian ini adalah atlet tenis lapangan putra UNP. Besar sampel yang digunakan dalam penelitian ini adalah 20 atlet tenis putra yang diperoleh dengan teknik purposive sampling dengan kriteria sebagai berikut: (1) petenis putra usia 20-25 tahun, (2) sampel mempunyai kemampuan yang relatif sama dalam bermain tenis lapangan, (3) sampel dalam kondisi sehat dan tidak sedang mengonsumsi obat-obatan.

\section{Instrumen dan Teknik Pengumpulan Data}

Instrumen untuk mengukur kadar glukosa darah menggunakan alat Glucometemelalui sampel darah yang diambil dari pembuluh darah kapiler pada ujung jari. Perlakuan (treatment) pada subjek penelitian diberikan saat waktu istirahat game ganjil selama 90 detik pada permainan tunggal tenis lapangan, yang menggunakan sistem permainan dua set. Perlakuan (treatment) yang diberikan kepada subjek penelitian berupa minuman isotonis dan pisang.

Jumlah minuman yang diberikan pada subjek penelitian yaitu $1200 \mathrm{ml}$, dikarenakan olahraga yang berdurasi lebih dari satu jam membutuhkan asupan cairan lebih banyak. Buah pisang diberikan sebanyak 5 biji dengan ukuran sedang. Perlakuan (treatment) diberikan dalam dua periode, yaitu periode pertama minuman isotonis, 
dan periode kedua buah pisang.. Masing-masing periode diberi jarak waktu tujuh hari yang bertujuan untuk menghilangkan efek antar perlakukan.

\section{HASIL PENELITIAN}

Deskriptif statistik data pretest dan posttest kadar glukosa darah pemain tenis lapangan setelah pemberian minuman isotonis dan pisang disajikan pada tabel 1 sebagai berikut.

Tabel 1. Deskriptif Statistik Pretest dan Posttest Kadar Glukosa Darah

\begin{tabular}{|c|c|c|c|c|}
\hline Jenis Treatment & Data & Statistik & $\begin{array}{c}\text { Hasil } \\
\text { Pretest }\end{array}$ & $\begin{array}{c}\text { Hasil } \\
\text { Posttest }\end{array}$ \\
\hline \multirow{2}{*}{$\begin{array}{c}\text { MINUMAN } \\
\text { ISOTONIS }\end{array}$} & \multirow{2}{*}{$\begin{array}{c}\text { Kadar Glukosa } \\
\text { Darah }\end{array}$} & Jumlah & 1825.00 & 1780.00 \\
\cline { 3 - 5 } & & Rerata & 91.2500 & 89.0000 \\
\cline { 3 - 5 } & \multirow{2}{*}{ PISANG } & Kadar Glukosa & 3.52248 & 3.22817 \\
\cline { 3 - 5 } & Darah & Jumlah & 1832.00 & 1711.00 \\
\cline { 3 - 5 } & & Rerata & 91.6000 & 85.5500 \\
\hline
\end{tabular}

Dari tabel $1 \mathrm{di}$ atas ada perbedaan nilai pretest dan posttest. Hasil yang baik terlihat jika nilai pretest dan postest tidak jauh berbeda. Nilai postest yang tinggi menggambarkan kadar glukosa darah yang baik. Oleh karena itu, jika semakin tinggi nilai postest, semakin baik pula kadar glukosa darah.

1) Hipotesis pengaruh pemberian minuman isotonis dan pisang terhadap kadar glukosa darah pemain tenis lapangan

a. Pengaruh pemberian pisang terhadap kadar glukosa darah

Tabel 2. Uji-t Hasil Pretest dan Posttest Kadar Glukosa Darah

\begin{tabular}{|c|c|c|c|c|c|c|}
\hline \multirow{2}{*}{ Kelompok } & \multirow{2}{*}{ Rata-rata } & \multicolumn{5}{|c|}{ t-test for Equality of means } \\
\cline { 4 - 7 } & & $\mathbf{t}_{\mathrm{ht}}$ & $\mathbf{t}_{\mathbf{t b}}$ & Sig. & Selisih & $\%$ \\
\hline Pretest & 91.6000 & \multirow{2}{*}{19,949} & 2,093 & 0,000 & 6.05000 & $6,60 \%$ \\
\hline Posttest & 85.5500 & & & & &
\end{tabular}

Dari hasil uji-t dapat dilihat bahwa $t_{\text {hitung }} 19,949$ dan $t_{\text {tabel2,093 (df 19) dengan nilai }}$ signifikansi $p$ sebesar 0,000 . Oleh karena $t_{\text {hitung }} 19,949>t_{\text {tabel }} 2,093$, dan nilai signifikansi $0,000<0,05$, maka hasil ini menunjukkan terdapat perbedaan yang signifikan. Dengan demikian hipotesis alternatif $(\mathrm{Ha})$ yang berbunyi“Ada pengaruh pemberian pisang terhadap kadar glukosa darah pemain tenis lapangan", diterima. Dari data pretest memiliki rerata 91,6, selanjutnya pada saat posttest rerata mencapai 85,55 . Besarnya pengaruh pemberian pisang terhadap kadar glukosa darah yaitu sebesar $6,60 \%$. 
b. Pengaruh pemberian minuman isotonis terhadap kadar glukosa darah Tabel 3. Uji-t Hasil Pretest dan Posttest Kadar Glukosa Darah

\begin{tabular}{|c|c|c|c|c|c|c|}
\hline \multirow{2}{*}{ Kelompok } & \multirow{2}{*}{ Rata-rata } & \multicolumn{5}{|c|}{ t-test for Equality of means } \\
\cline { 4 - 7 } & & $\mathbf{t}_{\mathrm{ht}}$ & $\mathbf{t}_{\mathrm{tb}}$ & Sig. & Selisih & $\%$ \\
\hline Pretest & 91.2500 & \multirow{2}{*}{7,784} & 2,093 & 0,000 & 2.25000 & $2,47 \%$ \\
\hline Posttest & 89.0000 & & & & & \\
\hline
\end{tabular}

Dari hasil uji-t dapat dilihat bahwa $t_{\text {hitung }} 7,784$ dan $t_{\text {tabel }} 2,093$ (df 19) dengan nilai signifikansi $p$ sebesar 0,000 . Oleh karena $t_{\text {hitung }} 7,784>t_{\text {tabel }} 2,093$, dan nilai signifikansi $0,000<0,05$, maka hasil ini menunjukkan terdapat perbedaan yang signifikan. Dengan demikian hipotesis alternatif $(\mathrm{Ha})$ yang berbunyi“Ada pengaruh pemberian minuman isotonis terhadap kadar glukosa darah pemain tenis lapangan", diterima. Dari data pretest memiliki rerata 91,25 , selanjutnya pada data posttest rerata mencapai 89,0 . Besarnya pengaruh pemberian minuman isotonis terhadap kadar glukosa darah yaitu sebesar $2,47 \%$.

\section{2) Hipotesis perbedaan pengaruh antara pemberian minuman isotonis dan} pisang terhadap kadar glukosa darah pemain tenis lapangan

Tabel 4. Hasil ANOVA Perbedaan Pengaruh antara Pemberian Minuman Isotonis dan Pisang terhadap Kadar Glukosa Darah

\begin{tabular}{|c|c|c|c|c|}
\hline Kelompok & Mean & $\boldsymbol{F}_{\text {hitung }}$ & $\mathbf{F}_{\text {tabel (df 2;57) }}$ & Sig. \\
\hline $\begin{array}{c}\text { Minuman } \\
\text { Isotonis }\end{array}$ & 89.0000 & \multirow{2}{*}{21.425} & 3.16 & 0,000 \\
\cline { 1 - 2 } Pisang & 85.5500 & & & \\
\hline
\end{tabular}

Dari hasil uji ANOVA tabel di atas dapat dilihat bahwa $F_{\text {hitung }}=21.425$ dan $F$ tabel (df $2 ; 57)=3,16$, sedangkan nilai signifikansi $p$ sebesar 0,000 . Karena nilai $F_{\text {hitung }}=21.425$ $>F$ tabel $(\mathrm{df} 2 ; 57)=3,16$ dan nilai signifikansi $p$ sebesar $0,000<0,05$, berarti ada perbedaan. Dengan demikian Ha diterima. Berdasarkan hasil analisis ternyata pemberian minuman isotonis lebih baik terhadap kadar glukosa darah pemain tenis lapangan dengan nilai rata-rata sebesar 89,0 dibandingkan dengan pemberian pisang. 


\section{SIMPULAN}

Berdasarkan hasil penelitian dan hasil analisis data yang telah dilakukan, diperoleh kesimpulan sebagai berikut:

1. Ada pengaruh pemberian minuman isotonis dan pisang terhadap kadar glukosa darah pemain tenis lapangan.

2. Ada perbedaan pengaruh antara pemberian minuman isotonis dan pisang terhadapkadar glukosa darah pemain tenis lapangan. Pemberian minuman isotonis lebih baik daripadapisang terhadap kadar glukosa darah.

\section{SARAN}

Berdasarkan hasil penelitian, maka kepada pelatih dan para peneliti lainnya, diberikan saran sebagai berikut:

1. Pelatih dan Atlet

Berdasarkan hasil penelitian yang telah dilakukan membuktikan bahwa pemberian minuman isotonis lebih baik daripada pemberian pisang terhadap kadar glukosa darah. Untuk itu disarankan kepada pelatih dan atlet untuk mengonsumsi minuman isotonis dan pisang dalam mempertahankan kadar glukosa darah.

2. Bagi Peneliti Selanjutnya

Hal ini merupakan kajian empirik yang dapat dipakai oleh para peneliti di bidang olahraga dalam melakukan inovasi untuk mempertahankan kadar glukosa darah. Untuk para peneliti yang bermaksud melanjutkan penelitian ini disarankan untuk melakukan kontrol lebih ketat dalam seluruh rangkaian eksperimen. Kontrol tersebut dilakukan guna menghindari ancaman dari validitas eksternal dan internal. 


\section{DAFTAR PUSTAKA}

Almatsier, S. (2009). Prinsip dasar ilmu gizi. Jakarta: Gramedia Pustaka Utama. Arikunto, S. (2013). Prosedur penelitian suatu pendekatan praktik. Jakarta: PT. Rineka Cipta.

Clark, N. (2014). Sports nutrition guidebookfifth edition. Newton: Human Kinetics.

Glaxo Smith Kline. (2008). The science behind sports drinks. Lucozade Sport Science.

Hadi, S. (2004). Metodologi research, jilid 4. Yogyakarta: Andi Press.

Hidayat, A. T., \&Fitranti, D. Y. (2014). Perbedaan kadar glukosa darah atlet setelah latihan antara pemberian sari tebu dan minuman berkarbohidrat pabrikan. Journal of Nutrition College, 3 (4), 880-886.

Horn, R. S. (2007). Blood sugar levels are stable. Diambil pada tanggal 17 Agustus 2018, dari http://medbio.info/

Irawan, M. A. (2007). Glukosa dan metabolisme energi. Sports Science Brief, 1 (6), 1-5.

Irianto, A. (2009). Statistik: konsep dasar \& aplikasinya. Jakarta: Kencana.

Irianto, D. P. (2007). Panduan gizi lengkap keluarga dan olahragawan. Yogyakarta: C.V Andi Offset.

Kaleka, N. (2013). Pisang-pisang komersial. Solo: Arcita.

Koswara, S. (2009). Minuman isotonik. Ebookpangan.com

Limbong, M., Jaya, R. D., \&Ariani, Y. (2015). Pengaruh relaksasi autogenik terhadap kadar glukosa darah pada pasien diabetes melitus tipe 2. Jurnal Skolastik Keperawatan, 1 (1).

Morrison, G., \&Hark, L. (1999). Medical nutrition and disease two edition. Massachusetts: Blackwell Science Inc.

Murray, B. (2007). Hydration and physical performance. Journal of the American College of Nutrition, 26 (5), 542S-548S.

Prabawati, S., Suyanti., \&Setyabudi, D, A. (2008). Teknologi pascapanen dan teknik pengolahan buah pisang. Badan Penelitian dan Pengembangan Pertanian.

Sharp, R. L. (2007). Role of whole foods in promoting hydration after exercise in humans. Journal of the American College of Nutrition, 26 (5), 592S-596S.

Sugiyono. (2013). Metode penelitian kuantitatif, kualitatif, dan $R \& D$. Bandung: Alfabeta.

Wibisana, R. (2013). Meraup uang dari bisnis olahan pisang. Yogyakarta: Sakti. 